\title{
INVENTÁRIO DO POTENCIAL PEDAGÓGICO DOS SÍTIOS DE GEODIVERSIDADE DO MUNICÍPIO DE PETROLINA-PE
}

\author{
Márcia Evangelista Sousa ${ }^{1}$ \\ Lucas Costa de Souza Cavalcanti ${ }^{2}$ \\ Luciana Freitas de Oliveira França ${ }^{3}$
}

\begin{abstract}
Resumo: Este trabalho trata da geodiversidade do município de Petrolina-PE, localizado no semiárido brasileiro. As paisagens locais são marcadas por serras, morros, serrotes, ilhas e campos de dunas vegetadas. Há uma carência de trabalhos detalhados sobre a geodiversidade local e este trabalho teve como objetivo avaliar o potencial pedagógico das paisagens para aulas de campo. O inventário baseou-se inicialmente na análise de cartas topográficas e foi complementado por observações de campo e consulta a mapas e trabalhos sobre a geologia local. Além disso, quantificaram-se os elementos da geodiversidade em cada local e os sítios foram classificados quanto ao seu potencial pedagógico em: potencial baixo, médio, alto ou muito alto. Foram identificados 32 sítios, apenas 1 deles com potencial pedagógico muito alto. Espera-se que estes sítios possam auxiliar a educação geográfica e interdisciplinar.
\end{abstract}

Palavras-chave: Paisagens naturais; Geodiversidade; Inventário; Potencial pedagógico; Petrolina

\section{INVENTORY OF THE PEDAGOGICAL POTENTIAL OF THE GEODIVERSITY SITES OF THE MUNICIPALITY OF PETROLINA-PE}

\begin{abstract}
This paper deals with the geodiversity of Petrolina municipality, located in Brazilian semi-arid. The landscapes of Petrolina presents hills, ridges, river islands and dune fields. There is a lack of geodiversity studies and this work proceeded an inventory of geosites evaluating its potential to field class. The inventory was based primary on analysis of topographical charts after complemented by field observations and check of geological papers and maps. Besides that was observed the proximity to roads, acess to geosites and safety questions. After this field class potential of geosites were classified as for quantity of geodiversity elements in: low, medium, high, and very high potential. Were found 32 sites of geodiversity, only 1 with very high potential. It's expected that this sites can help geographical and interdisciplinary education.
\end{abstract}

Keywords: Natural landscapes; Geodiversity; Inventory; Field class potential; Petrolina

\section{INVENTARIO DEL POTENCIAL PEDAGÓGICO DE LOS SITIOS DE GEODIVERSIDAD DEL MUNICIPIO DE PETROLINA-PE}

Resumen: Este artículo trata de la geodiversidad del municipio de Petrolina, ubicado en el semiárido brasileño. Los paisajes de Petrolina presentan colinas, crestas, islas fluviales y

\footnotetext{
${ }^{1}$ Mestra em Educação pela Universidade de Pernambuco - UPE. E-mail: marah-sousa@hotmail.com

${ }^{2}$ Professor Dr. do Departamento de Ciências Geográficas, Universidade Federal de Pernambuco-UFPE. E-mail: lucascavalcanti3@gmail.com

3 Professora Dra. do Departamento de Geografia, Universidade de Pernambuco-UPE. E-mail: lucianaagap@hotmail.com
} 
campos de dunas. Hay una falta de estudios de geodiversidad y este trabajo procedió a un inventario de geositios evaluando su potencial para la clase de campo. El inventario se basó principalmente en el análisis de cartas topográficas luego de completarse con observaciones de campo y verificación de documentos geológicos y mapas. Además se observó la cercanía a carreteras, acceso a geositios y cuestiones de seguridad. Después de este potencial de clase de campo de los geositios se clasificaron en cuanto a la cantidad de elementos de geodiversidad en: bajo, medio, alto y muy alto potencial. Se encontraron 32 sitios de geodiversidad, solo 1 con muy alto potencial. Se espera que estos sitios puedan ayudar a la educación geográfica e interdisciplinaria.

Palabras clave: Paisajes naturales; Geodiversidad; Inventario; Potencial pedagógico; Petrolina

\section{INTRODUÇÃO}

O reconhecimento internacional de sítios de geodiversidade e a constituição de geoparques apontam um novo caminho para o ensino de geociências. Contudo, a visitação a esses locais excepcionais não está acessível a todos, sobretudo para escolas em comunidades de baixa renda.

Explorar o potencial pedagógico das paisagens no entorno da escola é um desafio ao professor de Geografia. O inventário dos geossítios pode ser uma ferramenta útil para viabilizar o acesso de crianças e adolescentes ao conhecimento geológico local, fortalecendo laços identitários e de pertencimento geográfico e o empoderamento da comunidade.

Contudo, nem todas as paisagens apresentam a mesma diversidade de geossítios, de modo que os conteúdos a serem trabalhados precisam ser avaliados caso a caso. Além disso, o acesso aos geossítios pode não ser adequado para todas as faixas etárias, como no exemplo da severidade do meio em algumas localidades rurais.

Nesse sentido, há que se reconhecer que diferentes paisagens possuem distintos potenciais para uso pedagógico. Esse potencial precisa ser avaliado com cuidado pelo docente, considerando as evidências do tempo geológico à luz do currículo escolar, da faixa etária, demandas de estudantes especiais e a já mencionada severidade do meio.

O aproveitamento didático de sítios de geodiversidade tornou-se um elemento de notável relevância, uma vez que, além de possibilitar o conhecimento da geodiversidade, também propicia sua conservação, tendo em vista que o meio abiótico, muitas vezes, torna-se despercebido em detrimento da importância recebida pela biodiversidade.

Entende-se por geodiversidade a variedade de elementos abióticos como as rochas, o solo, fósseis e minerais. Muitos desses elementos constituem suporte para a biodiversidade 
como é o caso de paredões rochosos que desenvolvem algumas espécies vegetais típica desses ambientes, ou aves de rapina que procuram abrigo no alto dos penhascos (BRILHA, 2005).

Por outro lado, é bastante perceptível o destaque que se dá à biodiversidade quando relacionada à geodiversidade, já que tanto as leis ambientais como os projetos que visam proteger a natureza estão direcionados aos elementos bióticos (BRILHA, 2005; NASCIMENTO; AZEVEDO e MANTESSO-NETO, 2008; LOPES \& ARAÚJO, 2011), como é o caso do Projeto Tamar, que busca preservar espécies ameaçadas de extinção e o Projeto Sempre-Viva na Chapada Diamantina, que protege uma espécie de sempre-viva. Essas ações corroboram a grande atenção dada à biodiversidade e ao mesmo tempo ressalta a necessidade de desenvolver medidas que visem a conservação da geodiversidade.

Assim, o aproveitamento pedagógico de paisagens naturais que apresentam elementos abióticos relevantes torna-se um meio de divulgação e conservação da geodiversidade. Nesse sentido, apresenta-se a geodiversidade do sertão pernambucano, destacando os relevos residuais resultantes dos processos erosivos ocorridos no Nordeste brasileiro, os quais apresentam variedade de minerais e feições geomorfológicas diversificadas. Além disso, cabe salientar a presença de sedimentos do quaternário que testemunham períodos mais quentes que o atual representado pelas paleodunas, além do acúmulo de sedimentos no rio São Francisco que originou as ilhas fluviais.

Dessa maneira, o levantamento da geodiversidade do município de Petrolina permitiu conhecer as paisagens naturais e demonstrar a riqueza dos elementos abióticos, que as constituem, favorecendo a realização de aulas de campo.

Sendo assim, a avaliação dessas paisagens possibilitou descrever suas características, enumerando os elementos que podem ser explorados em trabalhos de campo. Essas paisagens apresentam riquíssimo potencial didático, abrangendo diversas áreas do conhecimento, como a Geografia, a Biologia, a Geologia e a Geomorfologia e, concomitantemente, favorecendo a realização de aulas interdisciplinares, reforçando, ainda mais, a eficácia dessa metodologia uma vez que, além de enfatizar os conteúdos didáticos, aborda também a degradação ambiental.

Portanto, evidencia-se a exploração dessas paisagens para o conhecimento dos elementos da geodiversidade por meio de aulas de campo, visto que essa prática contribui para a explicitação de conceitos em diversas áreas do conhecimento, que podem ser trabalhados tanto na educação básica (Ensino Fundamental II e Ensino Médio) como no Ensino Superior. Além do mais, essa metodologia permite trabalhar a educação 
contextualizada, ou seja, aliar os conteúdos a realidade em que o estudante está inserido, nesse caso o Semiárido brasileiro.

Diante disso, o presente trabalho teve como objetivo realizar o levantamento dos sítios de geodiversidade do município de Petrolina-PE, destacando o potencial pedagógico existente em cada um dos sítios avaliados, pois acredita-se que o uso didático favorece o desenvolvimento de medidas que proporcionam a conservação.

Vale ressaltar que a realização de aulas de campo de modo mais efetivo permitirá o conhecimento do patrimônio local, ao mesmo tempo em que auxiliará no desenvolvimento da sensibilização dos indivíduos da necessidade de se conservar o patrimônio natural.

\section{MATERIAIS E MÉTODOS}

\section{Localização da área de estudo e aspectos fisiográficos}

A área escolhida para o estudo foi o município de Petrolina (Figura 1), situado no sudoeste do Estado de Pernambuco, na região Nordeste do Brasil, entre as coordenadas geográficas $09^{\circ} 23^{\prime} 55^{\prime \prime}$ de latitude S e 40 30' 03" de longitude W. Segundo a CPRM (2005), esse município encontra-se a $722 \mathrm{~km}$ distante da capital Recife e está inserido na mesorregião do São Francisco e na Microrregião de Petrolina do Estado pernambucano.

O município de Petrolina está inserido na margem esquerda do rio São Francisco no Semiárido brasileiro, apresenta um clima semiárido do tipo BSh. Segundo a classificação de Köppen, ou seja, é um clima quente e seco, com altas temperaturas e elevado poder de evaporação, juntamente com baixa amplitude térmica e índice pluviométrico baixo (SEMAS, 2014a). Nesse sentido, a região do Submédio São Francisco é marcada por temperaturas médias de $27^{\circ} \mathrm{C}$, representando uma taxa de insolação de 2.800 horas, fator que justifica o alto índice de evapotranspiração, uma vez que a média anual chega a $1.550 \mathrm{~mm}$, enquanto a precipitação média varia de 350 a $800 \mathrm{~mm}$. Tais resultados permitem inferir o déficit hídrico que essa região apresenta (SEMAS, 2014b). 


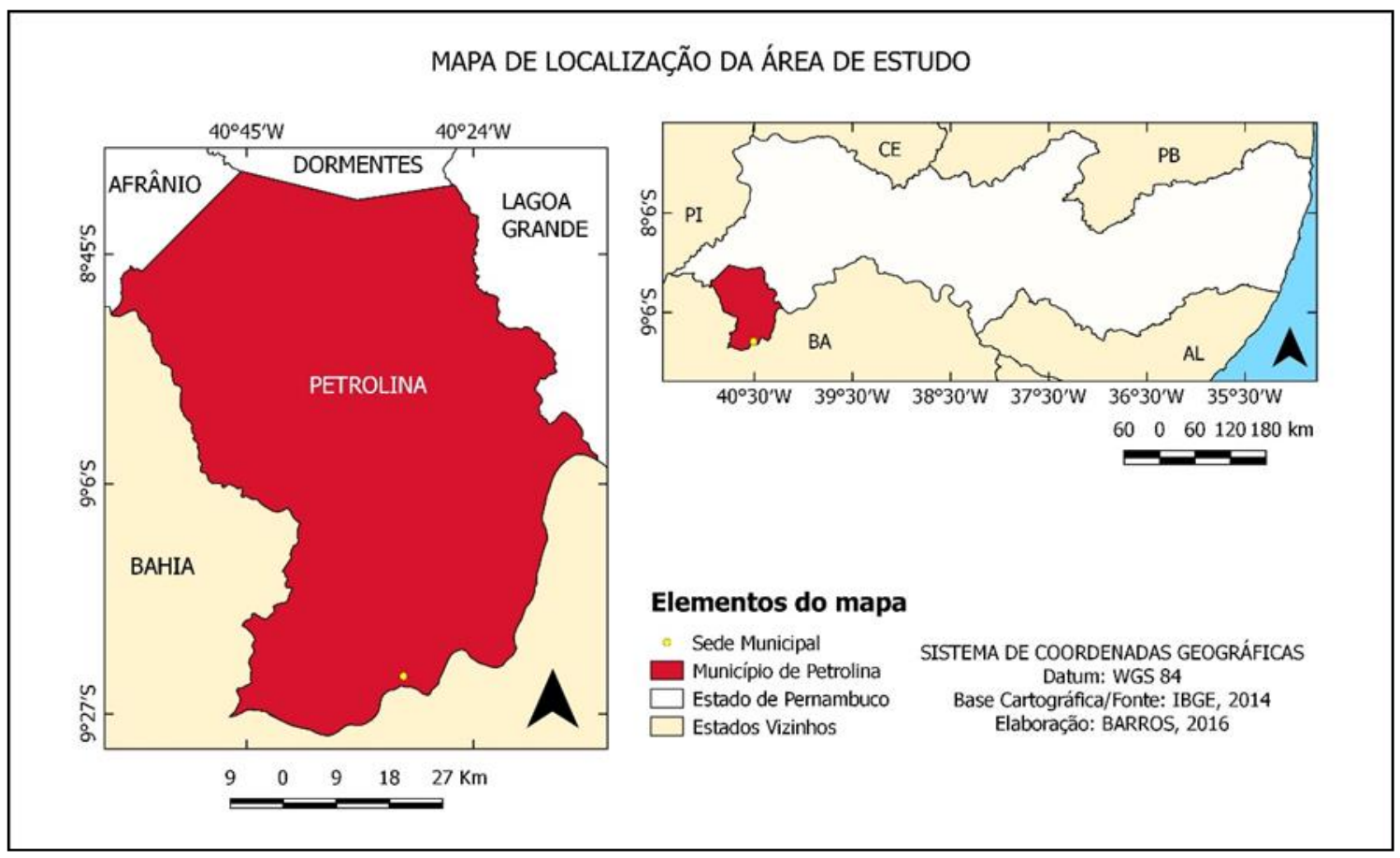

Figura 1- Localização da área de estudo. Fonte: Elaborado por BARROS, 2016.

Do ponto de vista geomorfológico, a área de estudo faz parte da unidade geoambiental da Depressão Sertaneja que, segundo a CPRM (2005), são representadas por superfícies de aplainamento e com a presença de relevos residuais a exemplo de cristas e morros, os quais corroboram os ciclos denudacionais que modelaram o relevo do semiárido nordestino. De acordo com a SEMAS (2014a, p.17), o município “Apresenta-se, em grande parte, como uma superfície de aplanamento retocada e recoberta por sedimentos, onde predominam processos de erosão além da ampla ocorrência de 'Inselbergs' devido ao modelamento policíclico, num sistema de erosão semiárido".

Quanto ao embasamento geológico, Petrolina está inserida no Cráton do São Francisco; entretanto, a parte norte do município fica na Província da Borborema. As paisagens avaliadas situam-se no setor Central do Cráton do São Francisco, o qual apresenta várias unidades litológicas e litoestratigráficas, entre essas, o grupo das unidades gnáissicas de formação paleo-mesoarqueanas, no qual o município está inserido (HASUI, 2012). Nesse âmbito, a CPRM (2005) ressalta que Petrolina é formada por litotipos do Complexo Gnáissico-migmatito Sobradinho/Remanso, do Greenstone Belt Rio Salitre, além de outros complexos, grupos e formações, dentre elas, as Colúvio-eluviais e Aluvionares.

Em relação aos tipos de solos, observa-se variedade, condicionados principalmente ao tipo de rocha e relevo, já que a região apresenta escassez hídrica. Assim, evidenciam-se os 
seguintes solos: Planossolos, Luvissolos, Latossolos, Argissolos, os Neossolos (Litólicos, Flúvicos, Regolíticos e Quartzarênicos). Os solos do município também apresentam grande risco de salinização (CPRM, 2005; SEMAS, 2014b), provavelmente resultante da falta de manejo e conservação do solo, associados ao uso intensivo de práticas de irrigação.

Segundo a CPRM (2005), o local de estudo está inserido na macro Bacia do rio São Francisco no trecho denominado Submédio, sendo formada pela bacia hidrográfica do Riacho do Pontal e pelo Grupo de Bacias de Pequenos Rios Interiores, as quais apresentam tributários com regime de escoamento temporário, com exceção do São Francisco.

Quanto aos domínios hidrogeológicos, a área está localizada no Domínio Hidrogeológico Intersticial e no Domínio Hidrogeológico Fissural, sendo o primeiro composto de sedimentos, entre elas, as paleodunas e o segundo, por rochas do embasamento cristalino, que variam entre metamórficas e ígneas (CPRM, 2005; SEMAS, 2014b).

Em relação à vegetação, o município de Petrolina é constituído pelo bioma caatinga, com espécies adaptadas ao clima quente e seco, apresentando vários mecanismos para sobrevivência nos períodos de escassez hídrica, a exemplo da presença de espinhos, folhas pequenas, armazenamento de água e nutrientes e perda das folhas (SEMAS, 2014b). Essas adaptações permitem o rápido florescimento após os longos períodos de estiagens.

A fisionomia da vegetação é bastante variada, tanto na densidade quanto no porte das plantas, sendo possível encontrar espécies herbáceas, arbóreas e arbustivas, podendo ser densas ou abertas. Entre as famílias que apresentam maior riqueza nessa região, estão as Fabaceae (principalmente Mimosoideae e Caesalpinoideae), Euphorbiaceae, Anacardiaceae e Cactaceae (SEMAS, 2014a).

\section{Procedimentos metodológicos}

O início do trabalho ocorreu com o levantamento bibliográfico sobre a temática em questão. Posteriormente, realizou-se o estudo dos dados geológicos, geomorfológicos e biogeográficos do município de Petrolina, por meio de pesquisas bibliográfica e documental em trabalhos publicados, imagens de satélites (Google Earth), mapas e cartas disponíveis.

Para a inventariação dos sítios, utilizaram-se as cartas topográficas do município de Petrolina, o qual está inserido nas Folhas da Superintendência do Desenvolvimento do Nordeste (SUDENE) de Riacho do Caboclo, Cristália, Itamotinga e Petrolina na escala 1:100.000. Verificaram-se as áreas de maior cota altimétrica para a identificação de serras, morros e serrotes. Também foram observadas nas cartas dezenas ilhas fluviais existentes na 
área de estudo; porém, a escolha desses sítios deu-se pelo uso e pela ocupação, principalmente a prática turística e residencial.

Outro critério utilizado foi o conhecimento científico sobre essas paisagens mediante de publicações, a exemplo da Proposta para Criação da Unidade de Conservação Parque Estadual Serra do Areal, em Petrolina/PE pela SEMAS - Secretaria de Meio Ambiente e Sustentabilidade (2014a) e dos trabalhos de conclusão de curso: Serra da Santa: Paisagem, cartografia e patrimônio (SANTOS, 2015); Caracterização paleoclimática e paleoambiental do campo de dunas de Petrolina em Pernambuco: um subsídio para a reconstituição do submédio São Francisco (CABRAL, 2014) e Evolução Geomorfológica e Paleoambiental das Bacias do Riacho do Pontal e GI-8 No Sub-Médio São Francisco (LIRA, 2014).

A partir do levantamento desses dados, foi elaborada uma tabela com as paisagens naturais do município, destacando a localização das mesmas para subsidiar os trabalhos de campo.

Assim, a pesquisa de campo ocorreu com a visita às paisagens selecionadas, nas quais foi realizado o registro das coordenadas geográficas e da altitude com uso de receptor GPS (Global Positioning System). Além da obtenção das informações cartográficas, avaliou-se o potencial pedagógico da paisagem, utilizando a ficha de campo, enquanto a descrição dos elementos mais relevantes foi realizada na caderneta de campo.

Os componentes e os processos que compõem e dinamizam as paisagens foram destacados na avaliação, entre esses, o uso e ocupação do solo para identificação do nível de degradação ambiental, como também o nível de dificuldade para realização do percurso. Além disso, foi realizado o registro fotográfico para demonstrar os aspectos mais significativos dos sítios avaliados.

\section{Avaliação do Potencial Pedagógico das Paisagens}

A avaliação do potencial pedagógico foi realizada em duas etapas. A primeira, foi a avaliação do conteúdo que pode ser trabalhado em campo, a partir do inventário de elementos da geodiversidade, e a segunda, foi feita por meio da observação das condições de acesso, ou seja, das dificuldades existentes no percurso.

A quantificação dos elementos da geodiversidade foi realizada por meio da aplicação da ficha de campo cujo propósito foi conhecer e descrever os elementos da paisagem, buscando avaliar o potencial pedagógico dos sítios, bem como o nível de degradação do ambiente e as condições de acesso ao local. A confecção da ficha teve como base a 
metodologia de Brilha (2015) para inventariação e quantificação de sítios de geodiversidade e a metodologia para a realização de trabalhos de campo de Cavalcanti (2014).

Nesse âmbito, o levantamento do potencial pedagógico foi realizado com base na quantidade de elementos da geodiversidade presente, uma vez que a ficha continha 22 elementos como: intrusões magmáticas, feições erosivas, dunas, morros, canal fluvial, etc. Esses elementos tiveram o propósito de quantificar o potencial pedagógico de cada sítio visitado.

Para isso, definiu-se a seguinte classificação: 1 a 4 elementos - baixo potencial pedagógico; 5 a 8 - potencial médio; 9 a 12 - alto potencial e; maior que 12 - potencial elevado. Essas informações permitiram enumerar o potencial didático dos sítios, levando em consideração a riqueza de elementos abióticos presentes, pois a diversidade deles contribui para a maior ou menor relevância didático-pedagógica da paisagem, visto que uma maior quantidade possibilitará maior exploração da área e, consequentemente, favorecerá melhor contribuição ao processo de ensino-aprendizagem.

Para conhecer o nível de degradação dos sítios elencaram-se as principais atividades desenvolvidas na região, a exemplo da agricultura, pecuária, mineração, entre outras. Assim, o risco de degradação foi determinado de acordo com o elevado número de funções exercidas no local. Dessa forma, categorizaram-se essas atividades com atribuição de pesos; assim, as práticas que apresentam maior poder de agressão ambiental receberam peso 3, as que têm poder intermediário receberam peso 2 , enquanto às que desencadeiam menor risco, foi atribuído peso 1. Com isso, a classificação do risco de degradação da paisagem teve como critério a somatória dos pesos de cada atividade. Nesse caso, as áreas que apresentaram valores de até 3 pontos foram consideradas de risco baixo; já as que tiverem de 4 a 5 pontos o risco foi médio, enquanto as que tiverem de 6 a 7 foram classificadas de alto risco e maior que 7, elevado.

Para analisar as condições de acesso, verificam-se as dificuldades encontradas no trajeto. Nesse caso, levantaram-se alguns dos itens mais comuns na realização de trabalhos de campos, entre estes: se o acesso é realizado por estrada de terra ou asfaltada, se há presença de trilha ou a necessidade do uso de GPS para chegar ao local. Também se averiguou se o trajeto é constituído por trechos íngremes e ocorrência de vegetação fechada, como também se há possibilidade de queda por escorregamento e dificuldade para utilizar serviços de urgência. Esse levantamento é um critério de limitação e de adequação das faixas etárias apropriadas ao contexto do percurso a ser visitado durante as aulas de campo. 
O critério estabelecido teve como base a quantidade de obstáculos presentes no roteiro de cada sítio, para a classificação do nível de dificuldade de acesso à paisagem. Posto isso, os trajetos que apresentaram de 1 a 3 obstáculos foram denominados de baixo nível; os que tinham 4 a 6, de nível médio; com 7 a 10 alto nível e maior que 10, elevado; enquanto os sítios que não tinham acesso foram denominados inacessível.

Após a aquisição dos dados do campo, juntamente com a análise de imagens de satélites (Google Earth) e de radar (SRTM), confeccionou-se o mapa do potencial pedagógico dos sítios de geodiversidade do município de Petrolina, utilizando o software QGIS, no qual se utilizou a fonte de dados do IBGE (2015) para se obter melhor visualização dos limites do munícipio, visto que apresenta discrepância quando comparado com as cartas topográficas e as imagens do Google Earth.

\section{RESULTADOS E DISCUSSÃO}

A geodiversidade do município de Petrolina é representada por serras, morros, serrotes, ilhas e paleodunas. A escolha desses sítios ocorreu por meio da análise das cartas topográficas e da divulgação científica de alguns deles, permitindo a seleção de trinta e dois sítios. Durante as visitas de campo, avaliou-se o potencial pedagógico dos sítios, aplicando a ficha de campo, que foi elaborada com o propósito/finalidade de levantar a quantidade de elementos abióticos em cada local visitado, pois a variedade de elementos indica uma maior ou menor diversidade de conteúdo a ser trabalhado.

O mapa abaixo (Figura 2) apresenta a localização e o potencial pedagógico dos sítios de geodiversidade do município de Petrolina, com base na representação dos elementos abióticos, sendo constituído por trinta e dois sítios classificados em: cinco serras, quatorze morros, nove serrotes, três ilhas e uma paleoduna. 


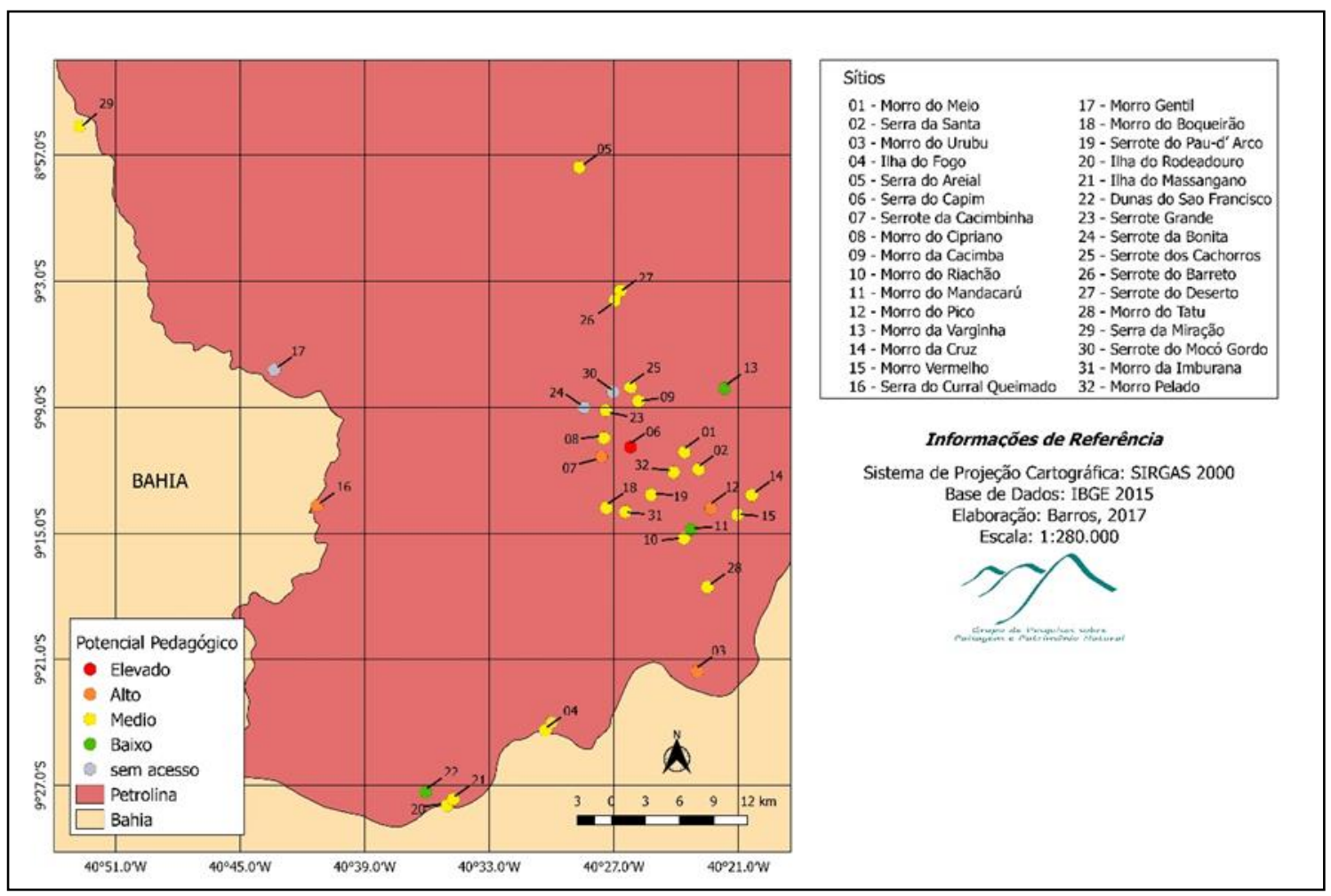

Figura 2- Localização e potencial pedagógico dos sítios de geodiversidade. Fonte: Elaborado por BARROS, 2017.

Entre as principais características dos sítios, notou-se que a maioria das serras, morros e serrotes apresentam litologias semelhantes, sendo constituídas por rochas metamórficas (gnaisses) e, na maioria delas, está presente a ocorrência de intrusões magmáticas, representadas por veios e diques de quartzo e pegmatitos. Além disso, são bastante comuns bastante comum áreas de rochas expostas, com vários afloramentos rochosos. No entanto, as Serras do Areial, do Curral Queimado, da Miração e o Morro do Pico diferenciam-se completamente das demais. As outras paisagens que apresentam elementos distintos são as Ilhas e a Paleodunas, apresentando litologia diferenciada, visto que se trata de áreas de deposição, ficando vulneráveis às alterações do meio em que estão inseridas.

Além disso, foi enumerada a representatividade dos elementos abióticos encontrados em cada sítio avaliado, ou seja, em quantos sítios esses elementos estavam presentes, o que permitiu a criação de um gráfico (Figura 3) da representação dos elementos da geodiversidade. Esses sítios apresentam uma variedade de elementos abióticos que podem ser explorados didaticamente. 


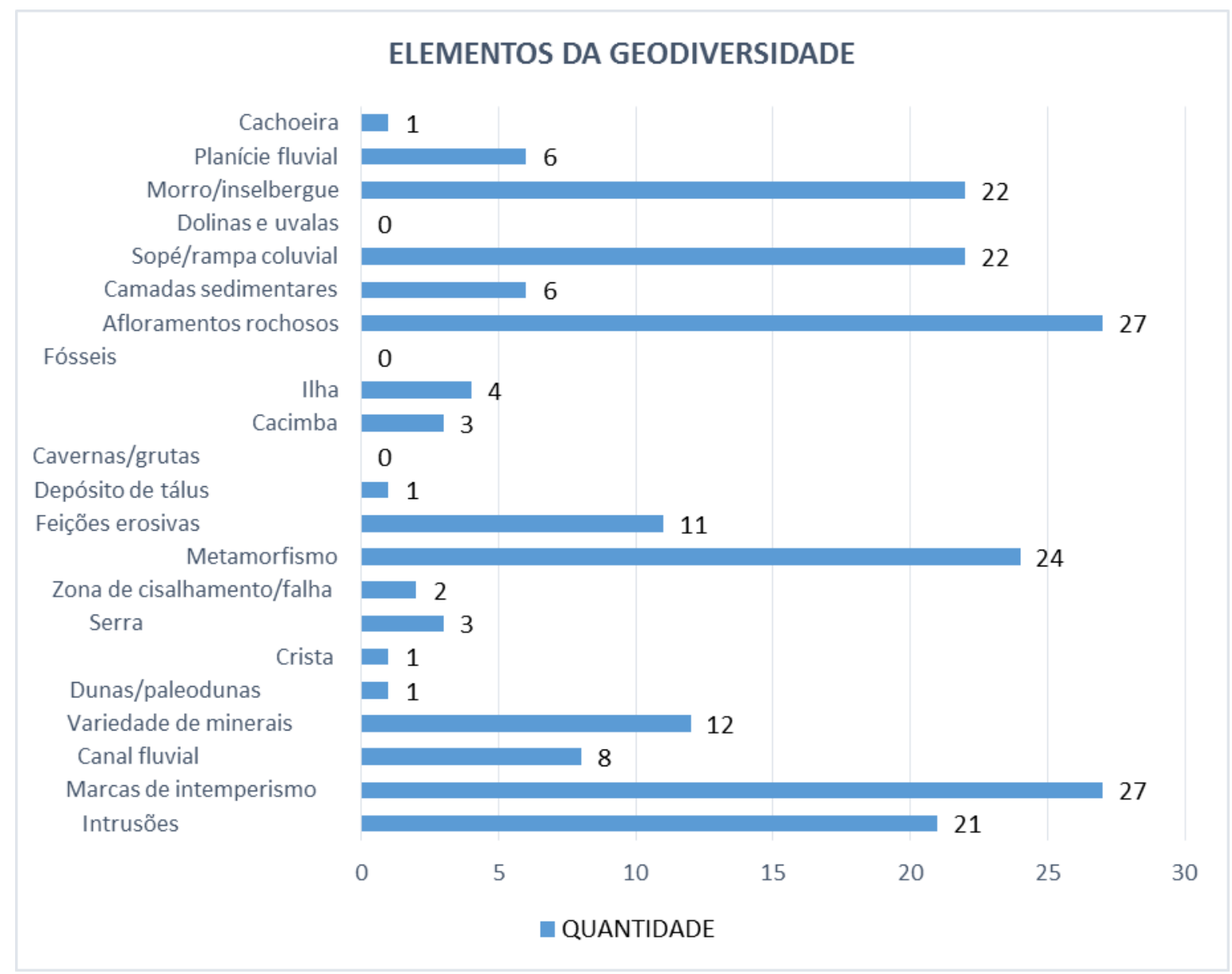

Figura 3- Representação dos elementos da geodiversidade. Fonte: SOUSA, 2017.

Quanto à predominância dos elementos da geodiversidade presentes nos sítios avaliados, verificou-se maior presença de afloramentos rochosos, marcas do intemperismo, metamorfismo e intrusões magmáticas, enquanto os demais elementos apresentaram quantidade menor, como a cachoeira, que só foi verificada apenas em um sítio. No entanto, alguns elementos presentes na ficha não foram encontrados a exemplo de cavernas e fósseis.

Os sítios avaliados, além de permitirem a exploração de vários aspectos da geodiversidade durante os trabalhos de campo, oportunizam o conhecimento de outros atributos como o uso e a ocupação do solo e as consequências do manejo inadequado dos recursos naturais.

O levantamento do potencial pedagógico das paisagens naturais de Petrolina possibilitou o mapeamento de trinta e dois sítios de geodiversidade. Tais sítios ressaltam o valor educacional da geodiversidade abordado por Brilha (2005; 2015). Nesse âmbito, as presentes paisagens avaliadas contemplam vários elementos abióticos, que podem ser explorados em aulas de campo. 
As paisagens avaliadas apresentaram resultados satisfatórios quanto ao seu potencial pedagógico, diante da quantidade de elementos naturais que podem ser trabalhados em aulas de campo. No entanto, levando em consideração as condições de acesso, três sítios não permitem a visitação em decorrência das dificuldades existentes no percurso. Desse modo, dos vinte e nove sítios investigados, apenas três apresentaram baixo potencial, enquanto vinte e um demonstraram médio potencial, quatro alto e um elevado potencial, como mostra o quadro abaixo.

A classificação do potencial pedagógico dos sítios de geodiversidade do município de Petrolina foi realizada por meio da utilização da ficha de campo para a quantificação dos elementos da geodiversidade. Assim, os sítios que apresentavam até quatro elementos foram classificados de baixo potencial, os que tinham de cinco a oito com médio potencial, enquanto os que mostraram de nove a doze foram classificados de alto potencial e com mais de doze elementos, caracterizados como elevado potencial pedagógico.

Quadro 1- Potencial Pedagógico dos sítios de geodiversidade de Petrolina.

\begin{tabular}{|c|c|c|c|c|c|}
\hline \multirow{2}{*}{ NOME DO SÍTIO } & \multicolumn{4}{|c|}{ POTENCIAL PEDAGÓGICO } & \multirow{2}{*}{$\begin{array}{c}\text { NÃO } \\
\text { VISITADO }\end{array}$} \\
\hline & BAIXO & MÉDIO & ALTO & ELEVADO & \\
\hline \multicolumn{6}{|l|}{ Dunas do S. Francisco } \\
\hline \multicolumn{6}{|l|}{ Ilha do Fogo } \\
\hline \multicolumn{6}{|l|}{ Ilha do Massangano } \\
\hline \multicolumn{6}{|l|}{ Ilha do Rodeadouro } \\
\hline \multicolumn{6}{|l|}{ Morro da Cacimba } \\
\hline \multicolumn{6}{|l|}{ Morro da Cruz } \\
\hline \multicolumn{6}{|l|}{ Morro da Varginha } \\
\hline \multicolumn{6}{|l|}{ Morro do Boqueirão } \\
\hline \multicolumn{6}{|l|}{ Morro do Cipriano } \\
\hline \multicolumn{6}{|l|}{ Morro do Mandacarú } \\
\hline \multicolumn{6}{|l|}{ Morro do Meio } \\
\hline \multicolumn{6}{|l|}{ Morro do Pico } \\
\hline \multicolumn{6}{|l|}{ Morro do Riachão } \\
\hline \multicolumn{6}{|l|}{ Morro do Tatu } \\
\hline \multicolumn{6}{|l|}{ Morro do Urubu } \\
\hline Morro Gentil & & & & & \\
\hline
\end{tabular}




\begin{tabular}{|l|l|l|l|l|l|}
\hline Morro Pelado & & & & & \\
\hline Morro Vermelho & & & & & \\
\hline Serra da Miração/ Morro Branco & & & & & \\
\hline Serra da Santa & & & & & \\
\hline Serra do Areial & & & & & \\
\hline Serra do Capim & & & & & \\
\hline Serra do Curral Queimado & & & & & \\
\hline Serrote da Bonita & & & & & \\
\hline Serrote da Cacimbinha & & & & & \\
\hline Serrote da Imburana & & & & & \\
\hline Serrote do Barreto & & & & & \\
\hline Serrote do Deserto & & & & & \\
\hline Serrote do Mocó Gordo & & & & & \\
\hline Serrote do Pau-d' Arco & & & & \\
\hline Serrote dos Cachorros & & & & \\
\hline Serrote Grande & & & & \\
\hline
\end{tabular}

A ficha de campo utilizada para a quantificação contemplou também outros elementos, a exemplo, das condições do percurso, que além de ter identificado três sítios inacessíveis, classificou-os conforme o nível de dificuldade encontrado no trajeto, como mostra o quadro a seguir.

Quadro 2- Nível de dificuldade no acesso dos sítios.

\begin{tabular}{|l|c|c|c|}
\hline \multicolumn{1}{|c|}{ SítIOS } & $\begin{array}{c}\text { NÍVEL DE } \\
\text { DIFICULDADE }\end{array}$ & SíTIOS & $\begin{array}{c}\text { NíVEL DE } \\
\text { DIFICULDADE }\end{array}$ \\
\hline Dunas do S. Francisco & Baixo & Morro Pelado & Alto \\
\hline Ilha do Fogo & Baixo & Morro Vermelho & Alto \\
\hline Ilha do Massangano & Alto & Serra da Miração/ Morro & Branco \\
\hline Ilha do Rodeadouro & Baixo & Serra da Santa & Alto \\
\hline Morro da Cacimba & Elevado & Serra do Areial & Alto \\
\hline Morro da Cruz & Alto & Serra do Capim & Médio \\
\hline Morro da Varginha & Alto & Serra do Curral Queimado & Inacessível \\
\hline Morro do Boqueirão & Alto & Serrote da Bonita & Médio \\
\hline Morro do Cipriano & Médio & Serrote da Cacimbinha & Médio \\
\hline Morro do Mandacarú & Alto & Serrote da Imburana & Médio \\
\hline Morro do Meio & Alto & Serrote do Barreto & Alto \\
\hline Morro do Pico & Alto & Serrote do Deserto & \\
\hline
\end{tabular}




\begin{tabular}{|l|c|c|c|}
\hline Morro do Riachão & Baixo & Serrote do Mocó Gordo & Inacessível \\
\hline Morro do Tatu & Alto & Serrote do Pau-d' Arco & Médio \\
\hline Morro do Urubu & Baixo & Serrote dos Cachorros & Médio \\
\hline Morro Gentil & Inacessível & Serrote Grande & Elevado \\
\hline
\end{tabular}

Essa investigação possibilitou relacionar a faixa etária (Quadro 3) com as condições de acesso para a visitação da paisagem, em decorrência das limitações existentes no trajeto, uma vez que os sítios, que apresentam maior nível de dificuldade, não são indicados para crianças e adolescentes. As áreas de nível alto e elevado contêm trechos íngremes ou sem trilha; em outros casos, com vegetação espinhosa ou urticante e presença de animais peçonhentos. Também é possível o risco de insolação em algumas épocas do ano, devido às altas temperaturas e a baixa umidade do ar, sendo ideal a realização dos campos entre os meses de janeiro a julho.

Quadro 3- Relação das condições de acesso aos sítios com a faixa etária.

\begin{tabular}{|c|c|}
\hline $\begin{array}{c}\text { NÍVEL DE DIFICULDADE DA } \\
\text { PAISAGEM }\end{array}$ & FAIXA ETÁRIA SUGERIDA \\
\hline Baixo & 10 a 14 anos \\
\hline Baixo e médio & 15 a 17 anos \\
\hline Todos os níveis & $>18$ anos \\
\hline
\end{tabular}

A classificação proposta teve o objetivo de evidenciar o potencial pedagógico que as paisagens naturais apresentam, destacando a diversidade de elementos abióticos, que podem ser explorados durante aulas práticas de campo.

Sabe-se que a utilização de ambientes naturais apresenta grande relevância para a aprendizagem. Nesse sentido, Seniciato \& Cavassan (2004) enfatizam algumas contribuições da aula de campo realizada em ambientes naturais, principalmente por contemplar uma abordagem mais complexa, devido à menor fragmentação do conhecimento. Logo, a realização de aulas de campo, nas paisagens naturais de Petrolina, permitirá a contemplação de várias áreas do conhecimento.

Em relação aos elementos naturais encontrados nos sítios, verificou-se uma variedade de elementos geológico, geomorfológico, paleosedimentar (Figura 4) e mineralógico. Este último destaca-se por apresentar alguns minerais atípicos aos demais encontrados na região, a exemplo da turmalina encontrada no Morro do Pico e no Serrote Grande e da magnetita no Serrote do Barreto e do Deserto. 
Também vale ressaltar outros valores contidos nessas paisagens, como os valores ecológico, biológico e botânico (SILVA et al., 2007), uma vez que se encontra grande diversidade de espécies vegetais, principalmente representadas por espécies das famílias cactáceas e bromeliáceas, sem contar a riquíssima fauna da caatinga. Isso evidencia a relevância de trabalhar a geodiversidade juntamente com a biodiversidade, uma vez que ambas estão relacionadas.

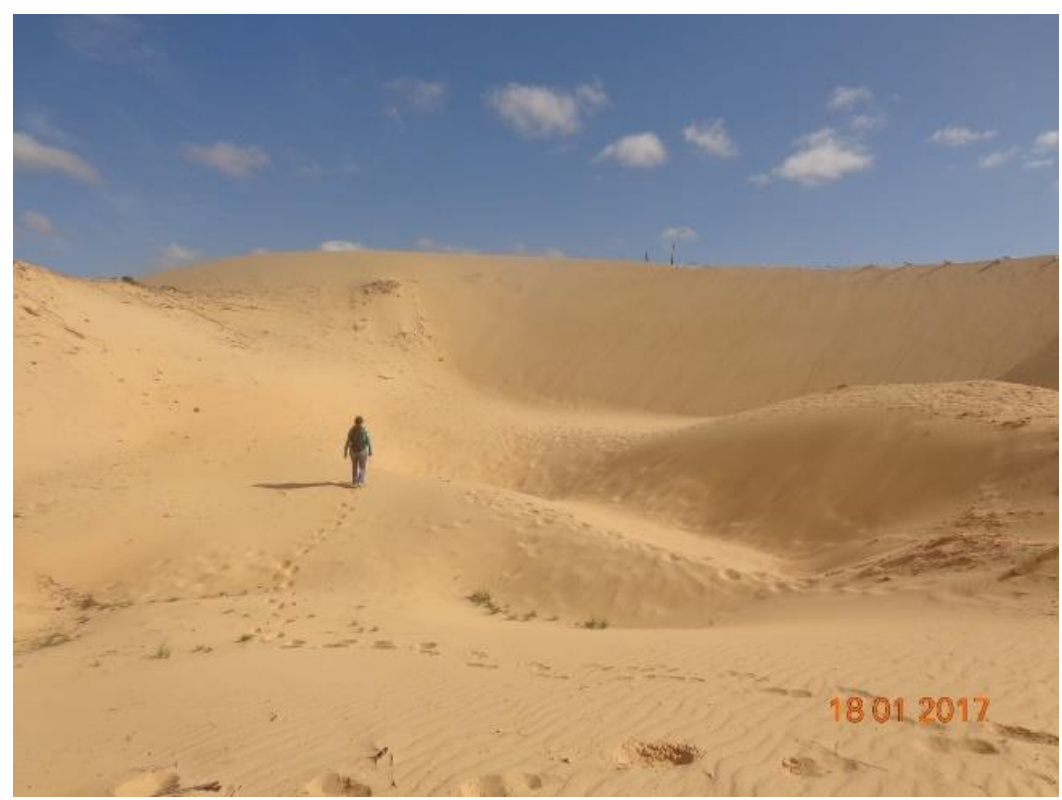

Figura 4- Depósito de sedimentos arenosos quaternários. Fonte: SOUSA, 2017.

Além dos componentes naturais existentes nos sítios avaliados, ocorre também a presença de elementos sociais, os quais são dotados de valores simbólicos como os valores: histórico, artístico, educacional, etc. (SILVA et al., 2007). Entre os valores propostos pelos referidos autores, verificaram-se o valor sagrado e o valor educativo, a exemplo do simbolismo religioso (Figuras 5A e B), uma vez que se constatou, em algumas paisagens de relevante cota altimétrica, a presença de cruzeiros no topo da elevação. Noutros casos, a existência de uma capela (Serra da Santa) e uma pequena "gruta" (Serrote do Barreto), nas quais ocorre a visitação de fiéis e realização de missas. 

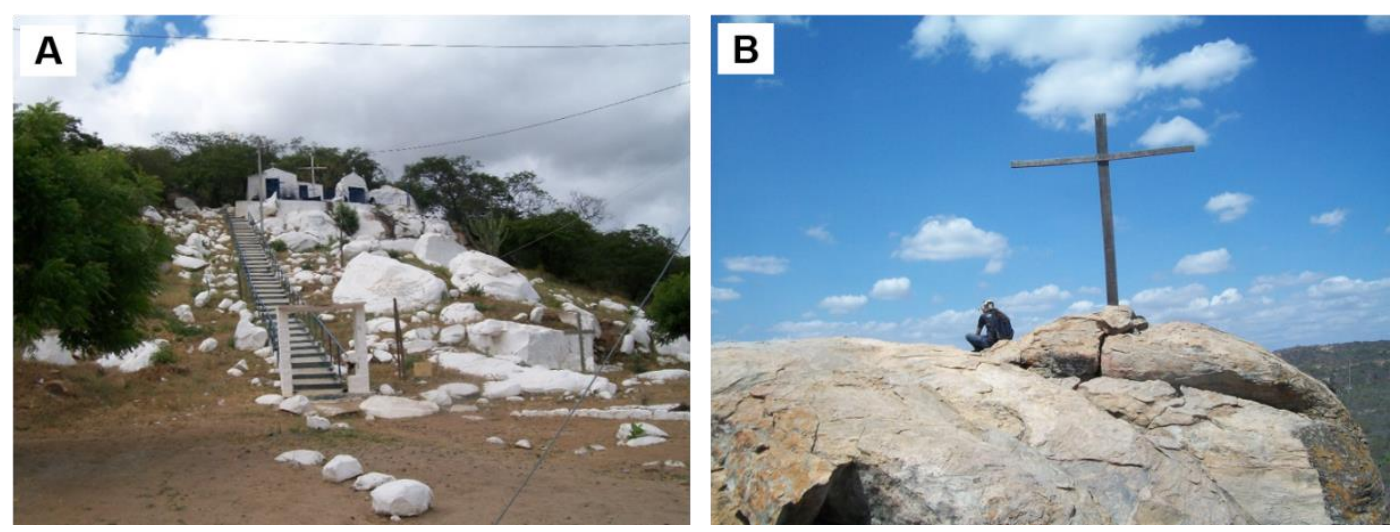

Figura 5- Valor sagrado. A) Igreja no sopé da Serra da Santa; B) Cruzeiro no alto do Serrote do Pau-d' Arco. Fonte: SOUSA, 2017.

O valor educacional está presente em todas as paisagens visitadas; no entanto, algumas apresentam maior variedade de elementos. Tendo como base a ficha aplicada para a quantificação do valor pedagógico, que leva em consideração a quantidade de elementos da geodiversidade, concluiu-se que o sítio de elevado potencial pedagógico do município de Petrolina é a Serra do Capim, apresentando treze elementos. Dentre os elementos, está a cachoeira (Figura 6), que não foi encontrada em nenhum outro sítio.

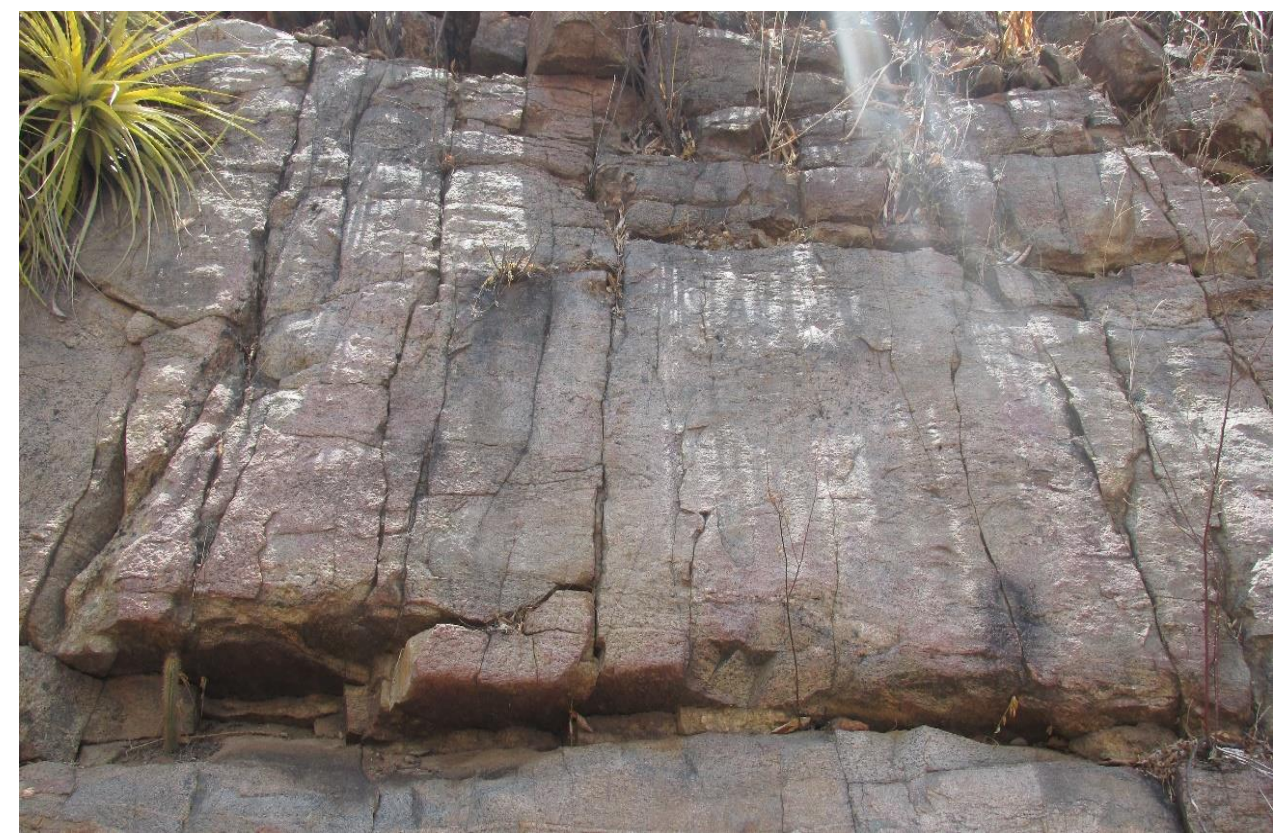

Figura 6- Cachoeira no sítio Serra do Capim. Fonte: BARROS, 2016.

Em relação aos valores da geodiversidade desenvolvidos por Gray (2004), as paisagens avaliadas contemplam todos, porém os valores educativo e econômico destacam-se entre os demais. 
Tendo conhecimento do quanto as atividades antropogênicas realizadas de forma inadequada contribuem desastrosamente para a degradação dos ambientes naturais, buscou-se identificar as principais atividades que aceleram a degradação dos sítios avaliados. Com isso, avaliou-se o risco de degradação dos sítios como mostra a figura 7, com base nas atividades antrópicas realizadas no local.

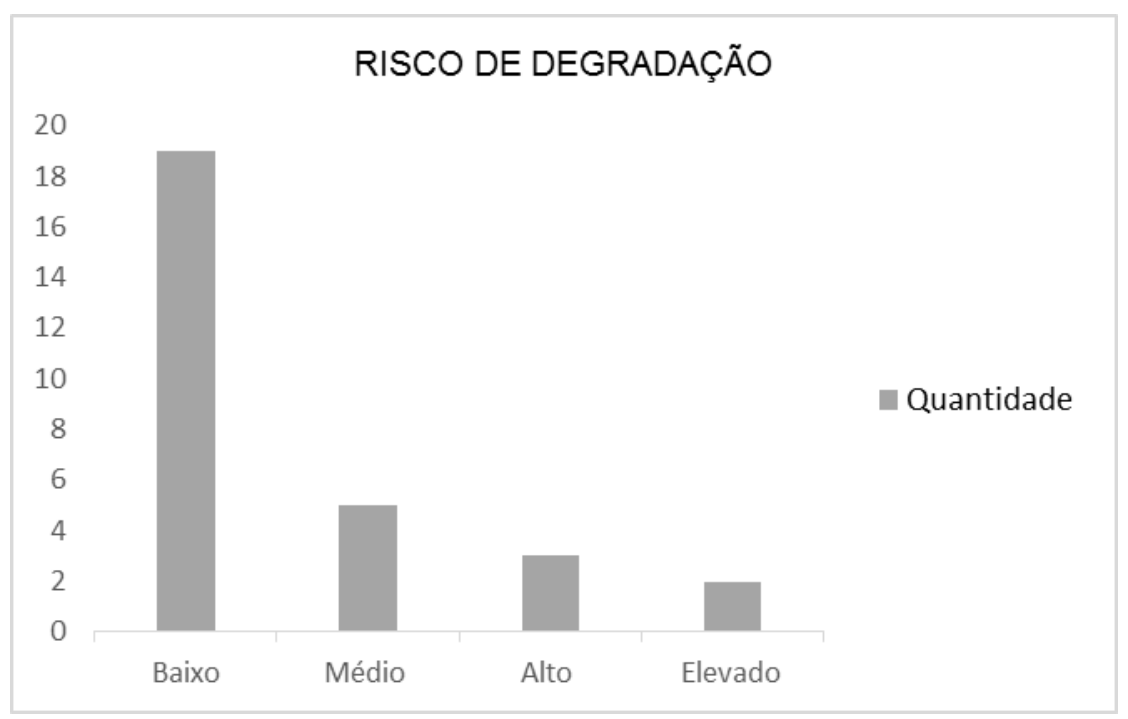

Figura 7- Risco de degradação dos sítios de Petrolina. Fonte: SOUSA, 2017.

Por meio dessa análise, concluiu-se que dos vinte e nove sítios avaliados a maioria apresenta risco de degradação baixo, porém três deles apresentam risco alto e dois, risco elevado, enquanto, as atividades verificadas com maior frequência nesses locais foram a mineração e a pecuária.

Os elementos abióticos apresentam grande vulnerabilidade, corroborando a necessidade de conservá-los. Daí a importância de se desenvolverem medidas que visem à sua conservação. Nesse sentido, a aula de campo surge como uma valiosa estratégia de geoconservação, ou seja, ela torna-se uma grande aliada na promoção da sensibilização da sociedade em relação aos danos ocasionados pela degradação ambiental, visto que foi verificado em alguns sítios grande risco de depredação do patrimônio natural devido ao uso inadequado do solo, principalmente a extração ilegal de rochas (Figura 8).

Como mostra a figura abaixo, a realização das atividades antrópicas não ocorre de maneira adequada, gerando grandes impactos aos ambientes naturais. Assim, a realização de trabalhos de campo os quais tenham como alvo promover a conservação do patrimônio natural, são grandes aliados na perspectiva de reduzir a degradação ambiental. Nesse sentido, Bento e Araújo (2014, p. 136) afirmam que “[...] quando o aluno conhece e se aproxima do 
local vivido, ele cria vínculos e ajuda na manutenção da preservação do local em questão". Com isso, percebe-se a significância das aulas de campo para a proteção dos recursos naturais.

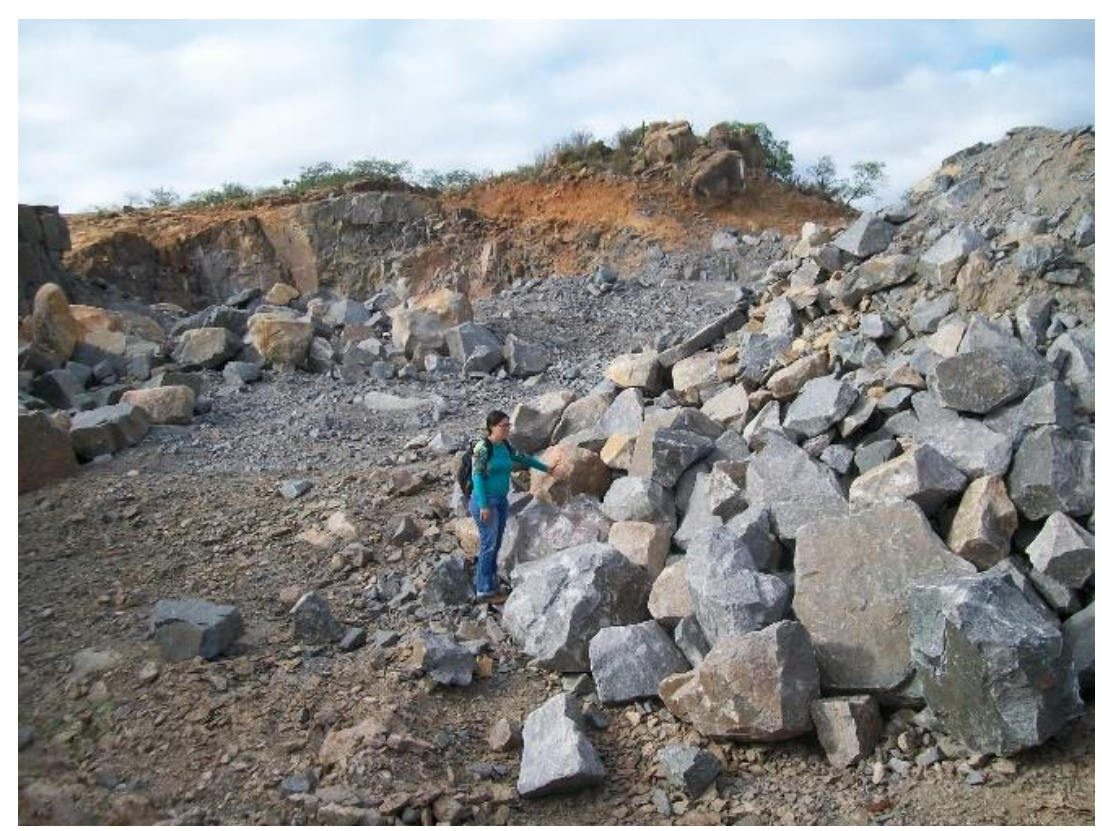

Figura 8- Degradação do patrimônio natural. Fonte: SOUSA, 2017.

Nesse âmbito, a utilização da prática de campo como metodologia de ensino torna o processo de ensino-aprendizagem mais significativo, pois oferece aos alunos meios para vivenciarem na prática o que foi apresentado nas aulas teóricas, tornando esse processo mais eficaz. Além disso, esse recurso didático viabiliza o desenvolvimento do senso crítico do estudante, uma vez que lhe é permitido conhecer o seu entorno e interpretar os problemas existentes, contribuindo para a transformação do seu meio através das habilidades adquiridas (SCORTEGAGNA \& NEGRÃO, 2005).

O conhecimento e a descrição dos aspectos dessas paisagens possibilitaram a enumeração do potencial pedagógico desses ambientes naturais para a realização de práticas de campo, visto que a quantificação do valor pedagógico de cada sítio buscou elencar os elementos da geodiversidade, que poderão ser abordados durante a realização de aulas de campo e a importância de conservar os elementos abióticos.

Em suma, a utilização das paisagens naturais no município de Petrolina, na realização de aulas de campo, contribuirá significativamente para a aprendizagem em todos os níveis de 
ensino, já que podem ser exploradas tanto por professores da educação básica como do ensino superior, contribuindo para uma maior difusão da geodiversidade do município.

O levantamento dos sítios de geodiversidade do município de Petrolina juntamente com a exposição do potencial pedagógico existente propiciará a ampliação do conhecimento do patrimônio natural desse município, uma vez que foram explicitados os elementos mais expressivos das paisagens naturais. E pensando na acessibilidade para a realização de aulas de campo, verificaram-se as condições de acesso, elencando o nível de dificuldade dos sítios, para auxiliar no desenvolvimento dos trabalhos de campo.

\section{CONSIDERAÇÕES FINAIS}

O estudo dessas paisagens destacou os principais elementos da geodiversidade, ao mesmo tempo que evidenciou o potencial pedagógico que elas apresentam. Nesse âmbito, o presente trabalho teve o propósito de enumerar os elementos abióticos mais significativos que constituem as paisagens petrolinenses, e as condições de acesso à essas paisagens, visando à divulgação da geodiversidade do município mediante a da realização de aulas de campo.

Assim, durante a análise dessas paisagens, foi possível avaliar o potencial pedagógico, com base na predominância de elementos da geodiversidade, como também averiguar o uso e a ocupação do solo, identificando as principais atividades antrópicas realizadas e os possíveis danos ocasionados ao ambiente. Após isso, percebeu-se, que dentre as atividades de maior intensidade, estão a pecuária e a mineração, as quais contribuem para a elevação do risco de degradação do patrimônio natural.

Em relação á dificuldade de acesso às paisagens avaliadas, concluiu-se que alguns dos sítios classificados com alto e elevado potencial pedagógico também apresentaram nível de dificuldade alto ou elevado, a exemplo do Morro do Pico e da Serra do Capim, limitando a acessibilidade, principalmente, às crianças e pessoas com deficiência. Para isso, sugere-se que o poder público municipal desenvolva obras de infraestrutura que visem à ampliação do acesso a essas áreas.

Essas informações foram primordiais para a enumeração dessas paisagens e da potencialidade didática que elas oferecem. Diante disso, propõe-se maior realização de aulas práticas de campo nos sítios apresentados, visando propiciar a alunos e professores o conhecimento do patrimônio local e o desenvolvimento de práticas sustentáveis que visem à conservação dos ambientes naturais. 


\section{Referencias Bibliográficas}

BENTO, L. C. M. Um novo olhar para a geodiversidade através do geoturismo. Enciclopédia Biosfera, Centro Científico Conhecer - Goiânia, vol.7, N.12; 2011, p. 159-166.

BENTO, L. C. M.; Araújo, M. S. Geoturismo e geoconservação: uma prática de campo. In: I SIMPÓSIO MINEIRO DE GEOGRAFIA, 2014, Alfenas. Anais... Alfenas, p. 132-145.

BRASIL. Lei No 9.985, de 18 de julho de 2000. Regulamenta o art. 225, § 1o, incisos I, II, III e VII da Constituição Federal, institui o Sistema Nacional de Unidades de Conservação da

Natureza e dá outras providências. Disponível em: <http://www.mma.gov.br/port/conama/legiabre.cfm?codlegi=322>. Acesso em: 10 out. 2016. Brasil. MINISTÉRIO DA INTEGRAÇÃO NACIONAL. Região Integrada de Desenvolvimento - RIDE Petrolina-Juazeiro. 2015. Disponível em: <http://www.mi.gov.br/c/document_library/get_file?uuid=e7f5d3d8-e874-4968-

8dda210b04e07026\&groupId=63635 >. Acesso em: 08 out. 2016.

BRILHA, J. Patrimônio Geológico e Geoconservação: A Conservação da Natureza na sua Vertente Geológica. Braga: Palimage Editores, 2005.

BRILHA, J. Inventory and Quantitative Assessment of Geosites and Geodiversity Sites: a Review. Geoheritage, v. 8, n.2, p. 119-134, 2016.

BRILHA, J.; DIAS, G.; PEREIRA, D. A Geoconservação e o Ensino/aprendizagem da Geologia. Simpósio Ibérico do Ensino da Geologia. In: XIV Simpósio sobre Enseñanza de La Geología, XXVI Curso de Actualização de Professores de Geociências. Universidade de Aveiro, Livro de Actas, 2006, p. 445-448.

BUENO, M. A. A importância do estudo do meio na prática de ensino em geografia física. B.goiano.geogr, Goiânia, v. 29, n. 2, p. 185-198, jul./dez, 2009.

CABRAL, C. J. Caracterização paleoclimática e paleoambiental do campo de dunas de Petrolina em Pernambuco: um subsídio para a reconstituição do submédio São Francisco. 153 f. Dissertação de Mestrado. Universidade Federal de Pernambuco. Recife, 2014.

CAVALCANTI, L. C. de S. Cartografia de Paisagens: fundamentos. São Paulo: Oficina de Textos, 2014.

CORDEIRO, J. M. P.; OLIVEIRA, A. G. de. A aula de campo em geografia e suas contribuições para o processo de ensino-aprendizagem na escola. Revista Geografia (Londrina), v. 20, n. 2, p. 099-114, 2011.

CPRM - Serviço Geológico do Brasil. Projeto cadastro de fontes de abastecimento por água subterrânea. Diagnóstico do município de Petrolina, Estado de Pernambuco/ Organizado [por] João de Castro Mascarenhas, Breno Augusto, Beltrão, Luiz Carlos de Souza Junior, Manoel Julio da Trindade G. Galvão, Simeones Neri Pereira, Jorge Luiz Fortunato de Miranda. Recife: CPRM/PRODEEM, 2005.

FRANÇA, L. F. de O.; MARIANO, G.; HORA, B. R. C. Avaliação quantitativa de sítios de geodiversidade utilizando a técnica de análise de agrupamentos: estudo de caso. Caderno de Geografia, v.26, n.45, 2016. ISSN 2318-2962.

GARCÍA-CORTÉS A, CARCAVILLA URQUÍ L. 2009. Documento metodológico para la elaboración del inventario español de lugares de interés geológico (IELIG), versión 12. Instituto Geológico y Minero de España, Madrid.

GRAY, M. Geodiversity: valuing and conserving abiotic nature. Londres: John Wiley \& Sons Ltd, 2004. 
HASUI, Y. Cráton São Francisco. In: HASUI, Y.; CARNEIRO, C.D.R.; ALMEIDA, F.F.M.; BARTORELLI, A. Geologia do Brasil. São Paulo: Beca, 2012. p. 200-227.

IBGE - Instituto Brasileiro de Geografia e Estatística. IBGE cidades. Disponível em: <http://www.cidades.ibge.gov.br/xtras/perfil.php?lang=\&codmun=2611101>. Acesso em: 07 out. 2016.

LIRA, D. R. de. Evolução geomorfológica e paleoambiental das bacias do Riacho do Pontal e GI-8 no Sub-Médio São Francisco. Tese (Doutorado em Geografia), Universidade Federal de Pernambuco, Recife. 2014, 234 p.

LOPES, L. S. de O.; ARAÚJO, J. L. L. Princípios e estratégias de geoconservação. OBSERVATORIUM: Revista Eletrônica de Geografia, v.3, n.7, p. 66-78, out. 2011.

NASCIMENTO, M.; AZEVEDO, Ú. R.; MANTESSO-NETO, V. Geodiversidade, geoconservação e geoturismo: trinômio importante para a conservação do patrimônio geológico. Rio de Janeiro: edição SBGeo, 2008.

NASCIMENTO, M. A. L do; RUCHKYS, U. A.; MANTESSO-NETO, V. Geoturismo: um novo segmento do turismo no Brasil. Global Tourism, v. 03, n. 2, nov de 2007, p. 1-24.

NEVES, K. F. T. V. Os trabalhos de campo no ensino de geografia: reflexões sobre a prática docente na educação básica. Ilhéus: Editus, 2010.

SANTOS, K. P. dos. Serra da Santa: Paisagem, cartografia e patrimônio. Trabalho de Conclusão de Curso, Universidade de Pernambuco. Petrolina, 2015.

SEMAS - Secretaria de Meio Ambiente e Sustentabilidade. Proposta para criação da unidade de conservação Parque Estadual Serra do Areal, em Petrolina / PE. Recife: Governo do Estado de Pernambuco, 2014 a.

SEMAS - Secretaria de Meio Ambiente e Sustentabilidade. Refúgio de Vida Silvestre Tatubola: Petrolina, Lagoa Grande e Santa Maria da Boa Vista Pernambuco (Proposta para Discussão). Recife: Governo do Estado de Pernambuco, 2014 b.

SCORTEGAGNA, A.; NEGRÃO, O. B. M. Trabalhos de campo na disciplina de Geologia Introdutória: a saída autônoma e seu papel didático. TERR $\boldsymbol{E}$ DIDATICA 1(1):36-43, 2005.

SENICIATO, T.; CAVASSAN, O. Aulas de campo em ambientes naturais e aprendizagem em Ciências - um estudo com alunos do ensino fundamental. Ciência \& Educação, v. 10, n. 1, p. 133-147, 2004.

SIGEP - Comissão Brasileira de Sítios Geológicos e Paleobiológicos. Disponível em: $<$ http://sigep.cprm.gov.br/>. Acesso em: 10 nov. 2016.

SILVA, A. de F.; BRAGA, A. C.; GAMEIRO, F. G.; LIRA, F. B.; SÁ CARNEIRO, A. R.; MELO, V. M. Os valores patrimoniais da paisagem cultural: uma abordagem para o processo de intervenção. Paisagem Ambiente: ensaios - n. 24 - São Paulo. 2007. p. 297 - 308.

SOUSA, M. E.; BARROS, R. G. de L; CAVALCANTI, L. C. de S. Práticas de campo em Geografia: valorização do potencial pedagógico das paisagens semiáridas. In: II Encontro de Geografia do Vale do São Francisco. Anais... Petrolina, 2016.

SOUSA, M. E. Potencial pedagógico das paisagens naturais de Petrolina, Pernambuco. Dissertação (Mestrado em Educação). 2017. 149 f. Universidade de Pernambuco -UPE, Petrolina, 2017.

Recebido em 31 de outubro de 2017.

Aceito em 17 de abril de 2018. 